\title{
Chapter 1 \\ Economics of Land Degradation and Improvement: An Introduction and Overview
}

\section{Ephraim Nkonya, Alisher Mirzabaev and Joachim von Braun}

\begin{abstract}
Land degradation is occurring in almost all terrestrial biomes and agro-ecologies, in both low and high income countries. However its impact is especially severe on the livelihoods of the poor who heavily depend on natural resources. Despite the severe impact of land degradation on the poor and the crucial role that land plays in human welfare and development, investments in sustainable land management (SLM) are low, especially in developing countries. This chapter summarizes the results from global and regional levels as well as 12 case study countries. The chapter also draws conclusions and implications for taking action against land degradation. Land degradation stretches to about $30 \%$ of the total global land area and about three billion people reside in degraded lands. The annual global cost of land degradation due to land use/cover change (LUCC) and using land degrading management practices on static cropland and grazing land is about 300 billion USD. Sub-Saharan Africa (SSA) accounts for the largest share (22\%) of the total global cost of land degradation. Only about $46 \%$ of the cost of land degradation due to LUCC — which accounts for $78 \%$ of the US $\$ 300$ billion lossis borne by land users and the remaining share $(54 \%)$ is borne by consumers of ecosystem services off the farm. This further illustrates that land degradation is a global problem even though its impact is much greater on poor land users. The cost of taking action against land degradation is much lower than the cost of inaction and the returns to taking action are high. On average, one US dollar investment into restoration of degraded land returns five US dollars. This provides a strong incentive for taking action against land degradation. This study shows that simul-
\end{abstract}

\author{
E. Nkonya $(\bowtie)$ \\ International Food Policy Research Institute, 2033 K Street NW, Washington, \\ DC 20006, USA \\ e-mail: e.nkonya@cgiar.org \\ A. Mirzabaev $\cdot$ J. von Braun \\ Center for Development Research (ZEF), University of Bonn, Walter Flex Str 3, \\ Bonn 53113, Germany \\ e-mail: almir@uni-bonn.de \\ J. von Braun \\ e-mail: jvonbraun@uni-bonn.de \\ (C) The Author(s) 2016 \\ E. Nkonya et al. (eds.), Economics of Land Degradation \\ and Improvement - A Global Assessment for Sustainable Development, \\ DOI 10.1007/978-3-319-19168-3_1
}


taneously enhancing local and national level governments, land tenure security, and improving market access is the most effective strategy for addressing land degradation. Given that LUCC accounts for the largest share of cost of land degradation, there is a need for developing land use planning that will ensure that forests and other high value biomes are effectively protected. Empirical evidence has shown that involvement of local communities in managing forests and other high value biomes and creating mechanisms for them to directly benefit from their conservation efforts lead to more effective protection than is the case with centralized protection. The assessment in this volume is being conducted at a time when there is an elevated interest in private land investments and when global efforts to achieve sustainable development objectives have intensified. This means, results of this volume will contribute significantly to the ongoing policy debate and efforts to design strategies for achieving sustainable development goals and other efforts to address land degradation and halt biodiversity loss.

Keywords Economics of land degradation and improvement - Sustainable land management $\cdot$ Cost of action $\cdot$ Ecosystem services

\section{Land Degradation: A Global Problem}

Sustainable land use and protection of soils play a key role in food, climate, and human security (Lal 2005, 2014; von Braun 2013; Lal et al. 2014; Amundson et al. 2015). In spite of this, land degradation has become a global problem occurring in most terrestrial biomes and agro-ecologies, in both low income and highly industrialized countries (Le et al. 2014; Chap. 4). On the other hand, fertile soils are a non-renewable resource by human time spans as their formation and renewal could take hundreds, if not thousands, of years (Lal 1994). For this reason, the human management of soil resources will have wide-ranging consequences on human security for generations to come.

Already, sharp acceleration in environmental pollution and natural resource degradation over the past century has led to a higher recognition of the importance of sustainable development, including the first global landmark event - the Human Environment Conference in Stockholm in 1972 (World Bank 2010). Continuing on this path towards sustainability, the United Nations have set 17 Sustainable Development Goals (SDGs) to guide the future global development agenda. One of the 17 targets aims to "protect, restore and promote sustainable use of terrestrial ecosystems, sustainably manage forests, combat desertification, and halt and reverse land degradation and halt biodiversity loss" (UNDP 2015). Thus, SDGs envision providing a global commitment to address land degradation and achieve a land and soil degradation-neutral world (Lal et al. 2012). 
Crucially in this context, the livelihoods of the majority of the rural poor depend on land (Nachtergaele et al. 2010). Additionally, food, fiber and other terrestrial ecosystem goods for the global population are drawn from land, the degradation of which has both direct and indirect impacts on overall human welfare. Addressing land degradation can, therefore, provide with cross-cutting contributions to achieving many of the other SDGs as well. Despite the crucial role that land plays in human welfare and development, investments in sustainable land management (SLM) are low, especially in developing countries. For example, public investments per worker in the agricultural sector in Sub-Saharan Africa (SSA) declined to one third from 152 USD in 1980-1989 to only 42 USD in 2005-2007 (FAO 2012). In particular, investments and incentives for sustainable land use and for prevention of land and soil degradation are presently inadequate and would need to be substantially increased in order to eradicate poverty and enhance food security in the world.

\section{Why Economics of Land Degradation and Improvement}

Given the above, the research presented in this book has been conducted with the objective to strengthen the foundations of ecological and economic knowledge that may stimulate putting sustainability of land and soils appropriately on the political agendas. These studies at global, regional and national levels evaluate the costs of land degradation and benefits of sustainable land management. They also identify the drivers of land degradation in order to devise polices to address them. Using case studies helps analyze in more detail the aspects of land degradation that cannot be captured using global or regional-level data, especially due to the diverse nature and process of land degradation under different biophysical and socio-economic characteristics at the local levels. A total of 12 country-level case studies were conducted for more detailed analyses of the costs and drivers of land degradation. The case study countries were carefully selected to be globally representative for major biophysical and socio-economic characteristics. They account for $43 \%$ of the global population and $28 \%$ of the land area.

The second objective of the volume is to provide empirical evidence and information to help the global community to take action against land degradation and its impacts on human wellbeing. The third objective of the study is to develop analytical approaches and generate data that could be used to conduct regular assessment of land degradation and improvement at global, regional, country and local levels.

The analytical methods are presented in a manner to allow their applications across disciplines and by researchers and practitioners with varying needs and capacities. The study covers two major categories of land degradation: namely, long-term loss of value of land ecosystem services due to land use and cover change (LUCC) and the use of land degrading management practices on cropland and grazing lands that do not experience LUCC. The six major biomes covered include forest, shrublands, grasslands, cropland, barren land, and woodlands and they accounted for about $86 \%$ of global land area in 2001 (NASA 2014). 
The broad research questions covered in this book include:

1. What are the appropriate and practical methods for global assessment of land degradation and improvement?

2. What are the global and regional extent and severity of land degradation and opportunities for improvement?

3. What are the key drivers of land degradation across typical socio-ecological regions of the world?

4. What are the economic, social and environmental costs of land degradation and net benefits resulting from taking actions against degradation compared to inaction?

5. What are the feasible policy and development strategies that enable and catalyze sustainable land management (SLM) actions?

The book makes two major new contributions. Firstly, it develops a conceptual framework to guide economic assessments of land degradation using the Millennium Ecosystem Assessment (MEA 2005), which defines land degradation as a long-term loss of ecosystem services (Chap. 2). Most previous studies on economics of land degradation concentrated on the impacts of land degradation on loss of provisioning services of croplandand grazing land and have ignored the loss of other ecosystem services (e.g. carbon sequestration and nutrient cycling) on agricultural land and other biomes. Secondly, this conceptual framework and the corresponding methodological approaches developed (Chaps. 2, 6 and 7) are consistently applied through comparable national case studies. Implementation of such harmonized case studies allows drawing more generalizable conclusions about the costs and drivers of land degradation. Most previous studies on economics of land degradation-while insightful locally - are much less comparable since they use different methods and approaches, and thus do not add up to a global picture.

Additionally, each chapter seeks to make more specific new contributions to the existing methodological, thematic or region-specific knowledge. Below we summarize major empirical findings of the chapters.

\section{Scale of Global Land Degradation}

Using remote sensing data, Chap. 4 identifies global hotspots of land degradation by correcting for biases found in previous mapping exercises, thus improving on the previous efforts on global land degradation mapping. The results show that land degradation stretches to about $30 \%$ of the total global land area and is occurring across all agro-ecologies. In total, there are about 3 billion people who reside in the areas with land degradation hotspots. However, the true number of people affected by land degradation is likely to be higher, because even those people residing outside degrading areas may be dependent on the continued flow of ecosystem goods and services from the degrading areas. One third of the area of land degradation hotspots is directly identifiable from a statistically significant declining trend in normalized 
difference vegetation index (NDVI), which is an index that measures the density of greenness of plants on a patch of land. However, the remaining two thirds of land degradation are concealed by rainfall dynamics, atmospheric fertilization and application of chemical fertilizers. Globally, human-induced biomass productivity decline is found in $25 \%$ of croplands and vegetation-crop mosaics, $29 \%$ of mosaics of forests with shrub- and grasslands, $25 \%$ of shrublands, and $33 \%$ of grasslands, as well as $23 \%$ of areas with sparse vegetation. The share of degrading croplands is likely to increase further when we take into account the croplands where intensive fertilizer application may be masking land degradation. Although this study does find land degradation to be a major problem in croplands, it also emphasizes, in contrast to most previous studies, the extent of degradation in areas used for livestock grazing by pastoral communities, including grasslands, shrublands, their mosaics, and areas with sparse vegetation. In most countries, livestock production and its value chains produce a comparable economic product and incomes for rural populations as crop production.

The results of this land degradation mapping were also groundtruthed in several dozen locations in six case study countries (Chap. 5). This evaluation showed an intermediate agreement between the mapping based on remotely sensed data and field results collected from focus group discussions with communities in six countries (Ethiopia, India, Niger, Senegal, Tanzania and Uzbekistan). In general, there was a higher agreement between the corrected NDVI results (Chap. 4) and focus group discussions (FGDs) on degraded lands than on lands which experienced improvement. The FGDs and field observations indicate that the results of the land degradation mapping are robust. This approach and its findings suggest that there may be ample opportunities for more "citizen research" and monitoring by communities on land degradation.

\section{Costs of Action and Inaction}

The annual costs of land degradation at the global level were found to equal about 300 billion USD $^{1}$ (Chap. 6). Sub-Saharan Africa (SSA) accounts for the largest share $(22 \%)$ of the total global cost of land degradation. The analysis of the cost of land degradation across the type of ecosystem services shows that $54 \%$ of the cost is due to the losses in regulating, supporting and cultural services (for example, carbon sequestration), which are considered as global public goods. Thus, the major share of the costs of land degradation affects the entire global community. The cost of taking action against land degradation is much lower than the cost of inaction. The benefits from investments into sustainable land management were found to exceed their costs by at least two times over a 30-year planning horizon globally. In many case study countries and sub-regions, the returns from each dollar of

\footnotetext{
${ }^{1}$ Unless otherwise stated, all values used in the cost of land degradation are in constant 2007 USD.
} 
investments into land rehabilitation were found to reach up to 5 dollars over the same period (Chaps. 11-21).

\section{Policies for Global and Regional Consideration}

In order to help in formulating policies and strategies for taking action against land degradation, Chap. 7 discusses the drivers of land degradation and improvement. The major factors affecting land degradation at the global level include land tenure security, population density, market access and rule of law. Better rule of law was found to positively influence sustainable land management in most cases, especially in sub-Saharan Africa. The areas with high population densities were found to manage their land resources more sustainably when they have a dynamic non-farm sector which facilitates cross-sector labor, technological and capital spillovers. Secure land tenure may provide additional benefits and opportunities for sustainable land management (SLM). With relatively well-functioning markets, including output, input and financial markets, land degradation also declines. Where markets do not function well or are very thin, secure land tenure may have much less effect on SLM. The findings further illustrate the key role played by governance and incentives for wider adoption of SLM practices.

Rangelands used by pastoral feeding systems account for $45 \%$ of ice-free land area (Asner et al. 2004) and $70 \%$ of the world agricultural land area (FAO 2008). Additionally, the demand for livestock products is rapidly increasing in both medium and low income countries. This underscores the importance of understanding the cost of land degradation on grazing lands. Therefore, Chap. 8 focuses on the analysis of the impacts of degradation on grazing lands that did not undergo LUCC - an area that accounts for $10 \%$ of the grasslands and about $6 \%$ of the total livestock population. The results show that the annual global cost of losses in milk and meat production due to grassland degradation is about 7 billion USD. Addressing grassland degradation could lead to win-win outcomes both in terms of lower poverty and higher carbon sequestration rates in grasslands.

Sub-Saharan Africa (SSA) experienced the most severe land degradation over the last decade and is also the region with the highest rates of poverty in the world. Chapter 9 analyzes the policies and land investments, the cost of land degradation and the drivers of land degradation and cropland expansion in the region. SSA has a large potential to become a global food breadbasket but presently faces daunting challenges. The analysis shows that the conversion of grassland to cropland and deforestation account for the largest share of the cost of land degradation in the region. The major driver of conversion of grassland to cropland is the low livestock productivity. Addressing this challenge requires an increase in the public allocations to livestock production and research, which currently represent only about $5 \%$ of the public budgets in the region. Efforts to improve grasslands through controlled grazing, planting legume crops, and other sustainable practices will 
increase both livestock productivity and carbon sequestration. The econometric results show tenure security, access to markets and government effectiveness are major factors for enhancing crop and livestock productivity and reducing land degradation. The analysis of cropland degradation shows an inverse relationship between profitability and adoption rates of sustainable land management practices. This is largely due to poor access to markets and credit, as well as low capacity of agricultural extension services to provide advisory services on SLM practices.

Chapter 10 analyzes land degradation in Central Asia - a region that has experienced a combination of extensive land degradation and fundamental institutional and economic transformations over the last three decades. This and other challenges have led to abandonment of large rainfed croplands, mainly in Kazakhstan, the continued desiccation of the Aral Sea, and wide-spread secondary salinization in the irrigated areas of the region, especially in the downstream of the region's two major rivers, Amudarya and Syrdarya. The annual costs of land degradation in Central Asia due to LUCC are about 6 billion USD. About 4.6 billion USD of the cost of land degradation are related with shifts from grasslands to lower value shrublands and barren lands. A total of about 14 million ha of grasslands have shifted to shrublands and barren lands in the region between 2001 and 2009, highlighting the massive problem of rangeland degradation. Another 0.75 billion USD were due to shifts from shrublands to barren lands, especially in the parts of the region near the Aral Sea, highlighting the growing problem of desertification. The loss of ecosystem services due to deforestation is about 0.32 billion USD, whereas the abandonment of croplands and their conversion to barren lands has resulted in about 110 million USD of losses, annually. The costs of taking action against land degradation are found to be 5 times lower than the cost of inaction over a 30-year period. Better access to markets, extension services, secure land tenure, and livestock ownership among smallholder crop producers are found to be major drivers of SLM adoptions. This further underlines the importance of tenure security and access to rural services in achieving sustainable land management.

There have been numerous but isolated attempts in the past to assess the causes and costs of land degradation at the national level. However, the differences in concepts and methodologies do not allow for their meaningful comparison, and quite often have led to contradicting policy conclusions. The series of country case studies included in this volume have been conducted in Asia, Europe, South America and sub-Saharan Africa using a standardized method, thus allowing for comparability of the results and drawing more generalizable conclusions (Chaps. 11-21). In the following section, we synthesize the major lessons learnt and the so-called "low hanging fruits" to address land degradation based on the global, regional and country case studies. The findings below are divided into individual strategies but an integrated approach involving several actions taken simultaneously is essential and could lead to bigger impacts and lower costs in addressing land degradation. 


\section{Lessons Learnt and Implications}

\section{Taking Action Against Land Degradation Due to Land Use/Cover Change (LUCC)}

The cost of land degradation due to LUCC accounts for $78 \%$ of the total global cost of land degradation of about 300 billion USD, suggesting that high priority should be given to addressing land degrading land use and cover change. There is a need for developing land use policies and planning that will ensure that forests and other high value biomes are protected and continue to provide ecosystem services both to local communities and to the global community (Chap. 6). The global efforts towards increasing protected areas have been successful, especially in the temperate areas. The deforestation rates in the tropical areas of the developing countries have also decreased significantly, but continue posing a big challenge (CBD 2014). There are still substantial deforestation and other forms of LUCC that need particular attention in the tropics and temperate regions. The conversion of forests into grazing lands was the major driver of deforestation in the Amazon region. In Central Asia, conversion of grassland to barren lands and shrublands was the major type of land degradation (Chap. 10), while in the SSA, the conversion of grassland to cropland was the leading cause of land degradation due to LUCC (Chap. 9). One of the major reasons for the conversion of grassland to cropland in SSA is the low livestock productivity. Strategies for addressing the conversion of grassland to cropland involve increasing livestock productivity, which may be more effective than enforcement of land use policies aimed at preventing LUCC. In general, the findings suggest that LUCC involving grasslands need to be given much higher attention than it has been the case so far. Empirical evidence has also shown that deforestation and sustainable forest management has been more likely in forests managed by local communities (Poteete and Ostrom 2004). Likewise, protected areas that involve local communities in management and who, in return, receive direct benefits have been more successful (Coad et al. 2008). This suggests strengthening community participation - a topic discussed in detail in the next section-is key to addressing degradation due to LUCC.

\section{Strengthening Community Participation for SLM}

Involving local communities and using their traditional knowledge and innovations are crucial to achieving effective conservation efforts. This is also consistent with the Aichi biodiversity target 18, which aims to respect and use traditional knowledge, innovations and practices of indigenous people and involve local communities in implementing conservation efforts (CBD 2014). Their involvement will ensure that they benefit and get rewarded for their protection efforts (Chap. 9). Such efforts could also involve payment for ecosystem services (PES), given that land 
degradation is a global "public bad", with the global community bearing a larger share of the cost of land degradation than the local community. Incentive mechanisms need to be developed to reward those who practice land management that provides significant global ecosystem services. This means that taking action against land degradation requires both local and global policies and strategies. However, experiences have shown that PES schemes did not work well in countries with poor markets and weak local institutions (Karsenty and Ongolo 2012). On the other hand, country-level PES schemes and policies that enhance incentives for investment in land improvement have also shown promising results, as illustrated in Niger (Chap. 19) and Costa Rica where the government collects a tax for PES and rewards land users who protect forests.

However, the low capacity of local communities to tackle technical issues of natural resource management is seen as a significant constraint that compromises effective SLM. This is especially the case for the relatively new paradigms such as integrated soil fertility management (ISFM), ecosystem service management and climate change (Chap. 9). This suggests the need to invest in training and awareness creation. For example, the Dankou forest program - a community-based forest management (CBFM) program in Senegal - spends about $54 \%$ of its budget for information and awareness (Chap. 19). Dankou CBFM has been very successful since the communities have been highly sensitized about the ecosystem services provided by the forests. As emphasized above, the technical support should take on board the indigenous knowledge and experience on ecosystem services. In other words, the information sharing and awareness creation should be two-way and sensitive to the indigenous communities.

A number of studies have shown that the pastoral systems in arid and semi-arid areas of Eastern Africa are generally sustainable even in the face of large biomass productivity changes largely due to the unpredictable precipitation and other natural shocks (Chaps. 8 and 9). There is a need to take advantage of the rich ecosystem knowledge of the pastoral nomadic communities in order to address the current challenges facing pastoral communities in the dry areas. As elaborated further, this will also require securing their communal grazing lands to stem the arbitrary expropriations and to invest in improvement of livestock productivity and marketing systems.

Strong customary institutions and environment-friendly cultural values could also be used for promoting sustainable land management. The case of strong cultural values in Bhutan (Chap. 12) illustrates the role played by cultural values in the protection of ecosystem services. Mahayana Buddhism places a strong value on the peaceful co-existence of people with nature and the sanctity of life and compassion for others. This is one of the major drivers of the high share (71\%) of the land area under forests in Bhutan and of the fact that $25 \%$ of the population lives in the protected areas. 


\section{Enhancing Government Effectiveness and Rule of Law}

The results at the global and regional levels, as well as in the case study countries consistently show that improved government effectiveness and rule of law enhance the adoption of sustainable land management practices. Improved government effectiveness works especially well when it gives local communities the mandate to manage their natural resources. For example, the key driver of Nigerien success story of tree planting and protection was improved government effectiveness, which simultaneously enabled communities to independently manage their natural resources and accrue direct benefits from their investments (Chap. 17). The country also learnt hard lessons from its past mistakes that involved policies which provided disincentives to land investment and the consequences of land degradation that were amplified by a prolonged drought.

In the past 20 years, government effectiveness has generally increased due to prolonged global democratic advocacies (Lynch and Crawford 2011). For example, development aid is given to developing countries which do not exercise flagrant undemocratic policies (Chap. 9). So in countries where rule of law is improving, SLM efforts are likely to yield favorable results (Chap. 7). This means that there may be more opportunities for addressing land degradation in countries which have shown significant improvements in government effectiveness and rule of law. Additionally, given that many donor programs require good governance as a condition for receiving aid, the donor community could continue this approach to promote government effectiveness and indirectly improve land management.

\section{Improving Access to Markets and Rural Services}

Controlling for government effectiveness and other important variables, access to markets could reduce the costs of land degradation (Chap. 9), and was consistently found to lead to wider adoption of SLM practices in several case study countries, such as Ethiopia, Malawi, Senegal, Tanzania and Uzbekistan (Chaps. 14, 19-21). In addition to increasing incentives, access to markets could help create alternative non-farm employment that could reduce pressure on land resources (Chap. 19).

In many developing countries, the capacities of agricultural extension services to provide advisory services on new approaches on integrated soil fertility management (ISFM), ecosystem services, climate change and other new paradigms is low (Chaps. 9 and 21). Likewise, there are limited advisory services on non-production technologies such as processing and marketing - the aspects which could contribute to enhancing SLM. This suggests the need to increase the capacity of agricultural extension agents to provide advisory services on SLM covering the entire value chain. The case study country results in Chaps. 11-21 show access to agricultural extension services improves tree planting (Bhutan) and adoption of SLM in general (Bhutan, Ethiopia, Kenya, Ethiopia, Malawi). Access to credit also increases the 
adoption SLM practices (Ethiopia, Malawi). In general, when major mediating factors - especially government effectiveness - are in place, improvement of rural services increases the adoption rates of SLM practices. For example, successful adoption of conservation agricultural practices in Argentina was achieved through strong extension services and public-private partnerships (Chap. 11). Conservation agriculture is considered as one of the best practices for sustainable land management (Lal 2015). This suggests the need to provide short-term training to agricultural extension agents and to incorporate the new paradigms in the agricultural curricula to ensure that future agents have greater capacity to provide appropriate advisory services. A pluralistic extension services could be required to achieve this objective since different providers will give complementary advisory services to cover many aspects where the traditional extension services might be deficient.

\section{Improving Land Tenure Security}

The findings from several case study countries have also consistently shown that adoption of sustainable land management practices is often dependent on secure land tenure (Tanzania, Malawi, Uzbekistan, and Ethiopia). Abdulai and Goetz (2014) establish similar relationships based on panel date analyses in Ghana. In this context, given that land prices and shadow prices are increasing due to the growing incomes, population and demand for biofuels and other alternative uses of agricultural products, land insecurity of the poor and vulnerable is becoming more acute. The recent trends in national and foreign land acquisitions in many developing countries, especially in SSA, illustrate this since such land acquisitions were concentrated in areas held under customary tenure and/or communal land with no formal tenure (Baumgartner et al. 2015). There is a need for policies which protect customary tenure systems against arbitrary expropriation. Additionally, long-term strategies for enhancing women's access to land under customary tenure need to be taken. Studies have shown that land markets improve women's access to land (Nkonya et al. 2008). This means, establishing land markets - especially in countries where land belongs to the government and land sales are illegal — could be one of the short-term term strategies for improving women's access to land.

\section{Going Forward}

The assessment in this volume is being conducted at a time when there is an elevated interest in private land investments and when global efforts to achieve sustainable development objectives have intensified (Chap. 2). For example, one of the 17 SDGs is specifically aimed at addressing land degradation and halt biodiversity loss. There have been numerous but isolated attempts in the past to assess 
the causes and consequences of land degradation (a review see in Nkonya et al. 2011). This study was done using a framework that could provide a consistent conceptual basis for other ongoing or future similar research activities and case studies on economics of land degradation and improvement.

The costs of land degradation are substantial and the costs of action to address land degradation are often several times lower than those of inaction. In spite of these high returns on investments in sustainable land management, land degradation is persisting, due to inadequate levels of investments in sustainable land management. There are two reasons for this, which need to be adequately addressed to incentivize more investments into SLM.

- First, as we have seen, the global costs of land degradation are higher than local costs, whereas the investments into SLM are often required from local land users, who include only the private costs of land degradation in their action calculations.

- Secondly, even in cases when the private costs of land degradation may be higher than the costs of inaction, many land users may be constrained in their actions by lack of knowledge of sustainable land management practices, access to markets, insecure land tenure, and other barriers to SLM.

Thus, the basic issue is that while land is, of course, local, costs and benefits of land (miss-) use are partly trans-regional and even global, i.e. land degradation is partly a global and national "public bad". Therefore policies and investments are needed to minimize the negative externalities of land degradation, for instance, by subsidizing sustainable land management.

The opportunity costs of taking action are main drivers that contribute to inaction in many countries. Strategies should be developed that give incentives to better manage lands and reward those who practice sustainable land management. The payment for ecosystem services (PES) mechanisms that saw large investments in carbon markets should be given a new impetus to address the loss of ecosystem services through land use/cover change (LUCC) which accounts for the largest cost of land degradation. Allowing landusers to internalize some of the positive externalities created by sustainable land management through PES schemes may be key to achieving a "land degradation neutral" world.

There is a need for strong emphasis on addressing land degradation in international and national investment programs.

The research on economics of land degradation needs to be increasingly based on comprehensive trans-disciplinary conceptual frameworks, such as Water-Energy-Food Security Nexus. However, this also necessitates further methodological advances in the valuation of ecosystem services and the inclusion of details of soil quality changes. Finally, there is a need for more research quantifying the long run impacts of land degradation on poverty and food security.

Sustainable land management is fundamental for humanity's sustainability in general. The land degradation trends must be reversed, and that makes economic sense. 
Open Access This chapter is distributed under the terms of the Creative Commons Attribution Noncommercial License, which permits any noncommercial use, distribution, and reproduction in any medium, provided the original author(s) and source are credited.

\section{References}

Abdulai, A., \& Goetz, R. (2014). Time-related characteristics of tenancy contracts and investment in soil conservation practices. Environmental \& Resource Economics, 59, 87-109.

Amundson, R., Berhe, A., Hopmans, J., Olson, C., Sztein, A. E., Sparks, D. (2015). Soil and human security in the 21st century. Science, 348(6235). doi:10.1126/science.1261071

Asner, G. P., Elmore, A. J., Olander, L. P., Martin, R. E., \& Harris, A. T. (2004). Grazing systems, ecosystem responses, and global change. Annual Review of Environment and Resources, 29, 261-299.

Baumgartner, P., von Braun, J., Abebaw, D., \& Müller, M. (2015). Impacts of large-scale land investments on income, prices, and employment: Empirical analyses in Ethiopia. World Development, 175-190.

CBD (Convention on Biological Diversity). (2014). Global biodiversity outlook 4. Montréal, 155 p.

Coad, L., Campbell, A., Miles, L., \& Humphries, K. (2008). The costs and benefits of forest protected areas for local livelihoods: A review of the current literature. UNEP-World Conservation Monitoring Centre: Cambridge, UK. Commissao Pastoral da Terra (2008). Online at http://apps.unep.org/publications/pmtdocuments/Cost_benefits_protected_forests_ area.pdf. Accessed 10 July 2014.

FAO. (2008). Are grasslands under threat? Brief analysis of FAO statistical data on pasture and fodder crops. Online at http://www.fao.org/ag/agp/agpc/doc/grass_stats/grass-stats.htm. Accessed 17 May 172015.

FAO (Food and Agriculture Organization). (2012). State of food and agriculture. Investing in agriculture for a better future. Rome: FAO.

Karsenty, A., \& Ongolo, S. (2012). Can 'fragile states' decide to reduce their deforestation? The inappropriate use of the theory of incentives with respect to the redd mechanism. Forest Policy and Economics, 18, 38-45.

Lal, R. (1994). Sustainable land use systems and soil resilience, In D. J. Greenland \& I. Szabolcs (Eds.), Soil Resilience and Sustainable Land Use (pp. 41-67). CAB-International, Wallingford, Oxon. UK.

Lal, R. (2005). Encyclopaedia of soil science (Vol. 1). CRC Press.

Lal, R. (2014). Societal value of soil carbon. Journal of Soil and Water Conservation, 69(6), 186A-192A.

Lal, R. (2015). Sequestering carbon and increasing productivity by conservation agriculture. Journal of Soil and Water Conservation, 70(3), 55A-62A.

Lal, R., Safriel, U., \& Boer, B. (2012). Zero net land degradation: A new sustainable development goal for Rio +20 . A report prepared for the Secretariat of the United Nations Convention to Combat Desertification.

Lal, R., Singh, B. R., Mwaseba, D. L., Karybill, D., Hansen, D., \& Eik, L. O. (2014). Sustainable intensification to advance food security and enhance climate resilience in Africa. Cham, Switzerland: Springer.

Le, Q. B., Nkonya, E., \& Mirzabaev, A. (2014). Biomass productivity-based mapping of global land degradation hotspots. ZEF-Discussion Papers on Development Policy, (193). ZEF, University of Bonn, Bonn, Germany.

Lynch, G., \& Crawford, G. (2011). Democratization in Africa 1990-2010: An assessment. Democratization, 18(2), 275-310. 
MEA (Millenium Ecosystem Assessment). (2005). Dryland systems. In R. Hassan, R. Scholes, \& N. Ash (Eds.), Ecosystem and well-being: Current state and trends (pp. 623-662). Washington, DC: Island Press.

Nachtergaele, F., Petri, M., Biancalani, R., Van Lynden, G., \& Van Velthuizen, H. (2010). Global land degradation information system (GLADIS). Beta version. An information database for land degradation assessment at global level. Land degradation assessment in Drylands technical report, no. 17. FAO, Rome, Italy.

NASA (National Aeronautic Space Authority). (2014). Moderate resolution imaging spectroradiometer (MODIS) data. Online at https://lpdaac.usgs.gov/. Accessed 20 Apr 2015.

Nkonya, E., Gerber, N., Baumgartner, P., von Braun, J., de Pinto, A., Graw, V., Kato, E., Kloos, J., Walter, T. (2011). The economics of land degradation. Towards an integrated global assessment. Development economics and policy, Band 66. Peter Lang.

Nkonya, E., Pender, J., Benin, S., \& Kato, E. (2008). Land rental markets and land management: Evidence from Uganda. In S. Holden, K. Otsuka, \& F. Place (Eds.), Emerging land markets in Africa-implications for poverty, equity and efficiency. Washington, D.C.: Resources For the Future Press.

Poteete, A., \& Ostrom, E. (2004). Heterogeneity, group size and collective action: The role of institutions in forest management. Development and Change, 35, 435-461.

UNDP (United Nations Development Program). (2015). Sustainable development goals proposals. Online at https://sustainabledevelopment.un.org/sdgsproposal. Accessed 21 Apr 2015.

von Braun, J. (2013). International co-operation for agricultural development and food and nutrition security: New institutional arrangements for related public goods (No. 2013/061). WIDER Working Paper.

World Bank. (2010). Development and climate change. World Development Report, 2010. Washington DC. 418 p. 